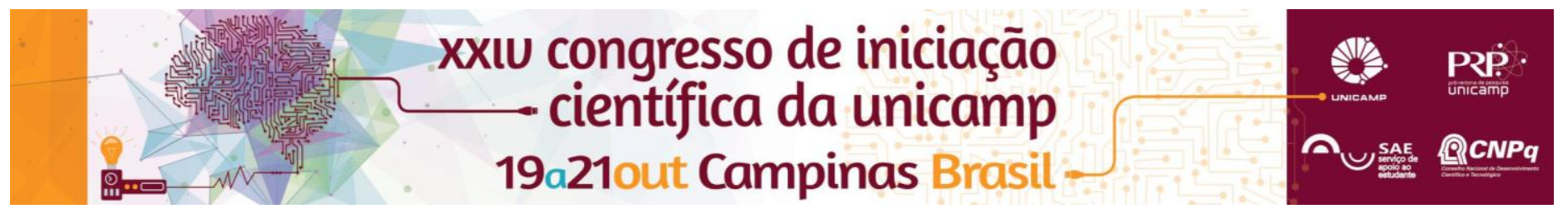

\title{
Efeitos antitumorais da associação de terapias anti-inflamatória e antiangiogênica sobre a progressão do câncer em camundongos transgênicos para o adenocarcinoma de próstata (TRAMP)
}

\author{
Pedro A. M. Mateus*, Larissa A. Kido, Rafael Sauce, Valéria H. A. Cagnon, Fabio Montico
}

\begin{abstract}
Resumo
A inflamação crônica tem sido relacionada à etiologia do câncer e drogas anti-inflamatórias, como o celecoxibe, têm sido testadas clinicamente como agentes quimioterápicos. A angiogênese também está estimulada no câncer, levando à formação de novos vasos sanguíneos para suprir as demandas metabólicas do tumor. Agentes antiangiogênicos, como o nintedanibe representam alternativas terapêuticas para retardar o avanço de tumores, inclusive na próstata. O objetivo foi avaliar a progressão do câncer, a distribuição do receptor androgênico (AR) e a densidade de microvasos positivos para o marcador CD31 na próstata ventral de camundongos TRAMP frente às terapias anti-inflamatória e/ou antiangiogênica. Camundongos TRAMP machos (12 semanas de idade) foram divididos nos grupos experimentais $(n=6)$ : A) Controle (TRCON): recebeu os veículos utilizados para diluição das drogas; B) Celecoxibe (TRCEL): tratado com celecoxibe (15 mg/kg), duas vezes ao dia; C) Nintedanibe (TRNTB): recebeu doses diárias de nintedanibe $(10 \mathrm{mg} / \mathrm{kg})$; e D) Nintedanibe + Celecoxibe (TRNTCEL): tratado com a combinação das drogas. Após 6 semanas de tratamento por via oral, amostras da próstata ventral foram coletadas para análise morfológica e imunohistoquímica. Os resultados demonstraram que o nintedanibe reduziu significativamente a incidência de focos de adenocarcinoma bem diferenciado (CP) em relação ao grupo controle, quando administrado isoladamente ou em associação com o celecoxibe. A terapia combinada também resultou em decréscimo significante de lesões do tipo neoplasia intraepitelial de alto grau (HGNIP). Tais efeitos observados nos grupos TRNTB e TRNTCEL associaram-se a uma menor distribuição do AR no epitélio prostático, sendo que, neste último grupo, houve também significativa redução na densidade de microvasos. Assim, concluiu-se que o nintedanibe é um agente antitumoral eficaz contra a progressão do câncer de próstata no modelo TRAMP. Além disso, sua associação com o celecoxibe demonstrou os benefícios da combinação de abordagens terapêuticas anti-inflamatórias e antiangiogênicas na interrupção ou atraso da tumorigênese prostática.
\end{abstract}

\section{Palavras-chave}

Celecoxibe, nintedanibe, TRAMP

\section{Introdução}

A inflamação crônica e a angiogênese são processos intimamente relacionados com a etiologia do câncer de próstata [1,2]. A ciclooxigenase-2 (COX-2) é uma enzima próinflamatória com efeitos tumorigênicos sobre a próstata, de modo que sua inibição pelo celecoxibe tem sido analisada para a prevenção e tratamento do câncer [1,3-5]. O nintedanibe (BIBF 1120), por sua vez, é um triplo inibidor de angioquinases, atuando sobre vias pró-angiogênicas [6]. Em adição, alterações da função do AR têm sido apontadas como um fator crítico para o desenvolvimento e progressão do câncer de próstata [7-9]. O objetivo deste estudo foi avaliar a progressão do câncer na próstata ventral de camundongos TRAMP frente às terapias com celecoxibe e/ou nintedanibe, correlacionando os achados morfológicos com a distribuição de AR e a densidade de microvasos no tecido prostático.

\section{Resultados e Discussão}

O nintedanibe reduziu significativamente a incidência de lesões mais avançadas, como o adenocarcinoma bem diferenciado (CP) e simultaneamente levou ao aumento da frequência de focos de neoplasia intraepitelial de baixo grau (LGNIP), quando administrado isoladamente ou em combinação com o celecoxibe. A combinação de nintedanibe e celecoxibe resultou ainda em decréscimo significante das lesões pré-malignas de alto grau (HGNIP) com potencial de evolução para focos de câncer. Os grupos TRNTB e TRNTCEL apresentaram diminuição significativa da distribuição epitelial de AR em relação ao TRCEL. Somente a DOI: 10.19146/pibic-2016-51824 associação de nintedanibe e celecoxibe resultou em decréscimo significante da densidade de microvasos.

\section{Conclusões}

$\mathrm{O}$ nintedanibe mostrou-se um agente antitumoral eficaz em inibir a progressão do câncer em camundongos TRAMP, provavelmente atuando negativamente sobre a expressão do AR. Além disso, a combinação com o celecoxibe resultou em efeitos antitumorais mais pronunciados, revelando assim o potencial quimioterápico deste anti-inflamatório. Assim, concluiu-se que a combinação das terapias foi mais eficiente que os tratamentos isolados, fato que destaca os benefícios da associação de agentes anti-inflamatórios e antiangiogênicos no combate a lesões malignas e pré-malignas da próstata.

\section{Agradecimentos}

À FAPESP e ao SAE/UNICAMP, pelo apoio financeiro.

\footnotetext{
${ }^{1}$ Elkahwaji, J. E., Res. Rep. Urol. 2013, 5, 1.

${ }^{2}$ Van Moorselaar, J. e Voest, E. E., Mol. Cell. Endocrinol. 2002, 197, 239.

3 De Nunzio, C.; Kramer, G.; Marberger, M.; Montironi, R.; Nelson, W.; Schröder, F.; Sciarra, A. e Tubaro, A. Eur. Urol. 2011, 60, 106.

${ }^{4}$ Hamid, A.R.; Umbas, R. e Mochtar, C.A. Acta Med. Indones. 2011, 43, 59.

${ }^{5}$ Sobolewski, C.; Cerella, C.; Dicato, M.; Ghibelli, L. e Diederich, M. Int. J.

Cell Biol. 2010, DOI: 10.1155/2010/215158.

${ }^{6}$ Awasthi, N. e Schwarz, R. OncoTargets and Therapy. 2015, 8, 3691.

${ }^{7}$ Debes, J. D. e Tindall, D. J. Cancer Letters. 2002, 187, 1

${ }^{8}$ Prins, G. S.; Birch, L. e Greene, G. L. Endoxrinology. 1991, 129, 3187.

${ }^{9}$ Cunha, G. R.; Hayward, S. W. e Wang, Y. Z. Differentiation. 2002, 70, 473.
} 